\title{
Hybrid CT-angiography to facilitate lower extremity sharp venous recanalization: a novel approach to a common procedure
}

\author{
Monica M. Matsumoto ${ }^{1 *}$ D, Karan Nijhawan², Jeffrey A. Leef ${ }^{2}$, Chelsea Dorsey ${ }^{3}$ and Osman Ahmed ${ }^{2}$
}

\begin{abstract}
Background: Post-thrombotic syndrome due to chronic venous occlusion is associated with high morbidity and healthcare costs. Sharp venous recanalization has been used with success when conventional techniques fail to cross the occlusion, permitting endovascular reconstruction with angioplasty and stenting. However, manipulation of a needle, especially in extra-anatomic locations, risks damage to adjacent structures, thus necessitating adequate imaging guidance.

Case presentation: This report describes the novel use of hybrid CT-angiography in a successful recanalization of a complex iliofemoral chronic venous occlusion, after multiple failed attempts with traditional recanalization techniques. The procedure was performed without complications, and stent patency was confirmed at three-month follow-up with patient-reported improvement in severe post-thrombotic syndrome.

Conclusions: This case demonstrates effective incorporation of hybrid CT-angiography to facilitate complex sharp venous recanalization for chronic lower extremity thrombosis, as an alternative to standard fluoroscopic techniques requiring multiple projections with or without cone-beam CT. Further studies are needed to understand the implications of this strategy.
\end{abstract}

Keywords: Angio-CT, Sharp venous recanalization, Post-thrombotic syndrome, lliocaval occlusion

\section{Background}

Post-thrombotic syndrome (PTS) is a common complication of deep vein thrombosis (DVT) and a major cause of morbidity and healthcare costs (Williams and Dillavou 2020). For PTS secondary to chronic iliocaval thrombosis in which standard endovascular reconstruction techniques fail to cross the occlusion, sharp recanalization has been reported with high technical success (McDevitt et al. 2019; Hage et al. 2018; Ito et al. 2012; Wadhwa et al. 2018). However, severe or moderate adverse events are reported in up to $5 \%$ of cases, so novel imaging methods beyond traditional fluoroscopic projection (with or without cone-beam computed tomography

\footnotetext{
* Correspondence: mmmatsumoto3@gmail.com

${ }^{1}$ Department of Radiology, University of Pennsylvania, 3400 Spruce Street, Philadelphia, PA 19103, USA

Full list of author information is available at the end of the article
}

(CT)) that allow safer needle guidance would be clinically relevant (McDevitt et al. 2019; Ito et al. 2012; Wadhwa et al. 2018; Tanaka et al. 2014). We present a case of severe PTS, in which hybrid CT-angiography (angio-CT) permitted improved visualization for sharp recanalization and venous reconstruction of a complex chronic left common iliac vein (LCIV) occlusion.

\section{Case presentation}

This case was exempt from the institutional review board. A 35-year-old male with a history of postoperative left lower extremity (LLE) DVT and recurrent right retroperitoneal Ewing sarcoma status postchemotherapy, radiation, resection, and spinal reconstruction complicated by LCIV injury and repair, presented to our emergency department with severe left groin pain and LLE heaviness/edema. He had been

\section{Springer Open}

(c) The Author(s). 2020 Open Access This article is licensed under a Creative Commons Attribution 4.0 International License, which permits use, sharing, adaptation, distribution and reproduction in any medium or format, as long as you give appropriate credit to the original author(s) and the source, provide a link to the Creative Commons licence, and indicate if changes were made. The images or other third party material in this article are included in the article's Creative Commons licence, unless indicated otherwise in a credit line to the material. If material is not included in the article's Creative Commons licence and your intended use is not permitted by statutory regulation or exceeds the permitted use, you will need to obtain permission directly from the copyright holder. To view a copy of this licence, visit http://creativecommons.org/licenses/by/4.0/. 
discharged three days prior from an outside hospital, where he had undergone three rounds of catheterdirected thrombolysis for extensive acute on chronic LLE DVT, but multiple attempts to recanalize the LCIV occlusion from above and below using standard catheter and wire techniques had failed. He was on therapeutic enoxaparin and reported no chest or abdominal pain and no fever, cough, or chills. LLE duplex ultrasound demonstrated acute DVT with complete occlusion of the distal left external iliac (LEIV) and common femoral (LCFV) veins, partial occlusion of the left deep femoral vein, and acute-on-chronic DVT with partial occlusion of the proximal LCFV. On follow-up with vascular surgery, he received extensive counseling on treatment options and was referred to interventional radiology (IR) for endovascular recanalization; venous-venous bypass was offered as a second option. Physical exam demonstrated pain to palpation of the left groin, as well as edema, erythema, and tenderness of the left thigh and leg. Range of motion and pulses were intact. His Villalta score of 16 was compatible with severe PTS, and recanalization was attempted (Soosainathan et al. 2013).

The initial LLE venogram confirmed the duplex ultrasound findings, and conventional recanalization attempts were unsuccessful (Fig. 1a), so the patient returned 1 month later for sharp recanalization under general anesthesia in a room equipped with angio-CT (Infinix-i 4DCT, Canon, Tustin, CA). Sheaths (Flexor; Cook Medical, Bloomington, IN) were placed in the right femoral vein (8F), LCFV (14F), and right internal jugular vein (RIJ) (8F) proximal to the iliac bifurcation. A 5F MPA catheter (Cook Medical) and 0.035" hydrophilic guide wire (Glidewire; Terumo Interventional Systems, Somerset, NJ) could not be advanced further into the LCIV (Fig. 1b). The RIJ sheath was exchanged for a RöschUchida transjugular liver access set (Cook Medical), EN Snare catheter systems (Merit Medical, South Jordan,
UT) were placed in the RIJ and LCFV accesses, and the LCIV was recanalized with needle puncture across the surgical clips into the extra-vascular space under fluoroscopy (Fig. 1c-d).

Hybrid-CT confirmed the extra-vascular location, as well as positioning of the snares (Fig. 2a). Under CT guidance, a $21 \mathrm{G}$ needle was advanced percutaneously through the snares. Under fluoroscopic guidance, an 0.018 " V-18 wire (Boston Scientific, Marlborough, MA) was advanced and snared through the LCFV access (Fig. 2a-c). Through-and-through "flossing" between the LCFV and RIJ accesses was achieved using a 0.035" guidewire. Angioplasty $(5 \times 20 \mathrm{~mm}$ Mustang; Boston Scientific) was performed over the LCIV and LEIV, followed by deployment of a Viabahn stent graft (13x50mm; Gore Medical, Flagstaff, AZ) across the extra-vascular connection site with post-dilation $(12 \times 40$ mm Mustang) (Fig. 3a). A Viabahn stent was chosen to cross the extra-anatomic portion as it is self-expanding and can cover any potential area of injury at this point. Additional Venovo stents $(16 \times 160 \mathrm{~mm}, 12 \times 60 \mathrm{~mm}$, $14 \times 60 \mathrm{~mm}$ ) (BD Bard, Tempe, AZ) were deployed in the LCIV and LEIV across the Viabahn with extension into the LCFV, followed by angioplasty $(14 \times 40 \mathrm{~mm}$ Atlas; BD Bard) (Fig. 3b). Rheolytic thrombectomy (AngioJet; Boston Scientific) was performed for acute thrombus throughout the LCFV and LEIV, with patency and restoration of normal luminal caliber on postthrombectomy venogram (Fig. 3c).

The patient tolerated the procedure well without major complications. Serial creatinine remained at baseline, and hematocrit returned to normal after $24 \mathrm{~h}$. The patient received a $300 \mathrm{mg}$ loading dose of clopidogrel, in addition to heparin drip for $36 \mathrm{~h}$, and was discharged on post-procedure day two on therapeutic enoxaparin and $75 \mathrm{mg}$ clopidogrel daily. He reported marked clinical improvement in leg swelling at one-week follow-up phone
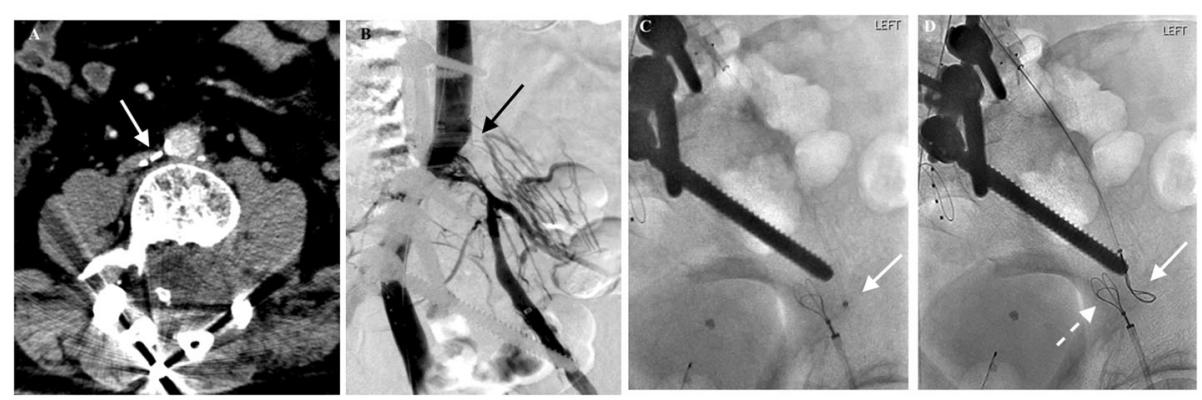

Fig. 1 a CT demonstrated clips at level of LCIV origin (arrow) from prior surgical ligation of the LCIV, which were likely contributing to chronic occlusion of the vessel and complex recanalization techniques required; $\mathbf{b}$ Initial LLE venogram in the extreme RAO view shows flush occlusion of LCIV (arrow), in addition to postoperative findings related to L4 corpectomy and posterior lumbar fusion hardware; c Sharp recanalization needle was advanced from the proximal LCIV in the direction of the LEIV into the extra-vascular pelvic space (solid arrow), thus bypassing the known occlusion, confirmed on hybrid CT; $\mathbf{d}$ The two snares could now be advanced above (solid arrow) and below (dotted arrow) the area of occlusion and were confirmed to be close to each other on both AP and oblique projections 

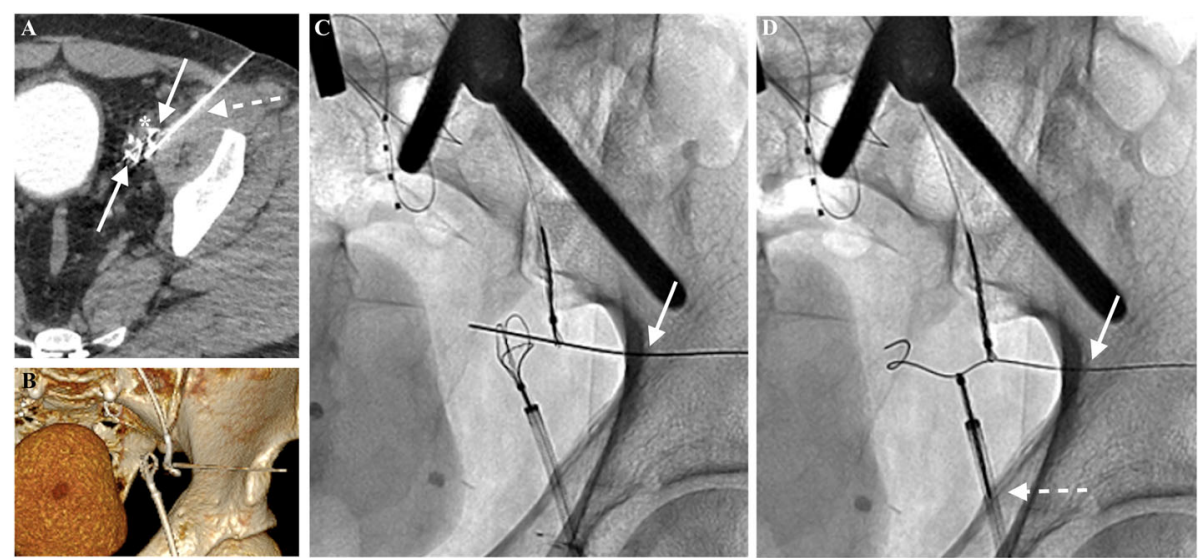

Fig. 2 a Axial hybrid CT images confirmed the two snares (solid arrows) in close proximity to each other, with an adjacent external iliac artery (asterisk). A 21G needle (dotted arrow) was advanced percutaneously through the snare catheters using intermittent CT guidance, allowing a safe trajectory to avoid puncture of the artery and to reduce the potential for damage to adjacent structures; $\mathbf{b}$ Additional three-dimensional reformat show the trajectory of the needle (arrows) through the vascular snares; c Switching from CT to fluoroscopy allowed real-time adjustment and advancement of the needle (arrow) through both snares while avoiding the artery, utilizing the "gun-sight" approach without complication (Haskal et al. 1996); d A V-18 wire (solid arrow) was advanced through the needle access and snared through the LCFV access (dotted arrow). The needle was safely removed under fluoroscopy, and through-and-through "flossing" access was achieved with the following technique: the wire and snare were pulled out from the groin access, and a 0.018" Quick-Cross catheter (Spectranetics, Colorado Springs, CO) was advanced over the wire through the superior snare and then snared from above with the wire removed. The wire was then re-advanced, snared, and pulled out from the neck access site

call. On three-month follow-up he underwent IVC filter removal and LLE venogram, demonstrating widelypatent LCIV and LEIV stents. His Villalta improved to 6. He is currently scheduled for six-month venous duplex ultrasound follow-up.

\section{Conclusions}

This case demonstrates strategic use of angio-CT to guide sharp recanalization of a chronic LCIV occlusion causing severe PTS in a patient with a complex surgical history and chronic occlusion refractory to prior recanalization attempts. Furthermore, long segment extra-anatomic sharp recanalization of the left iliocaval confluence left little room for technical error due to the proximity to the right iliac artery bifurcation (McDevitt et al. 2019; Ito et al. 2012). Given the need for precision and safety, angio-CT integrating volumetric CT fluoroscopy with fan beam CT machinery in the same room, as opposed to C-arm cone-beam CT, was utilized (Tanaka et al. 2014; Toyoda et al. 2009). The hybrid system is more frequently employed for interventional oncology and is not well described for chronic venous occlusions,
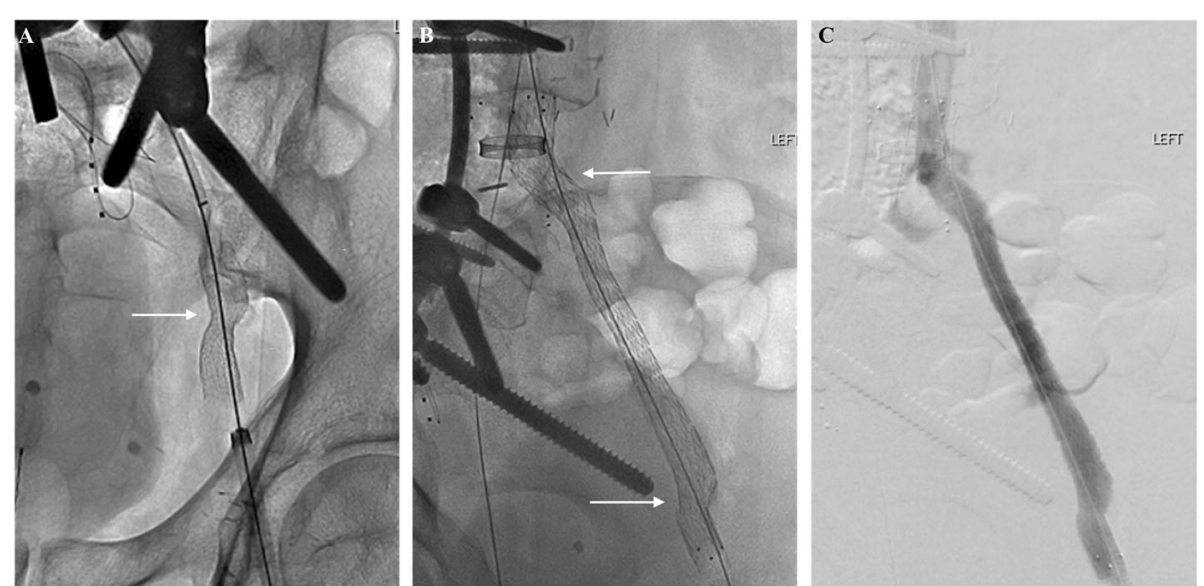

Fig. 3 a Following balloon angioplasty of the LCIV and LEIV, a $13 \mathrm{~mm}$ Viabahn endoprosthesis (arrow) was deployed across the site of the extravascular connection created; b Additional Venovo stents (arrows) were deployed in the neo-LCIV and LEIV across the Viabahn with extension into the LCFV; c Post-angioplasty venogram showed patency of the left femoral and neo-iliac veins with restoration of normal luminal caliber 
but it assisted in completing this case efficiently and safely in the setting of spinal hardware and iliac artery proximity, with a larger axial field-of-view, improved real-time anatomic discrimination, quick interchanging between modalities, and artifact reduction with similar radiation doses to fan beam CT (Tanaka et al. 2014). Similar techniques would have been difficult with conebeam CT, which requires either the $\mathrm{C}$-arm to spin around the patient producing lower-quality images or fluoroscopy in multiple orthogonal planes. This case report demonstrates the utility and feasibility of incorporating angio-CT in complex sharp venous recanalization. Further studies are needed to understand the implications of this strategy.

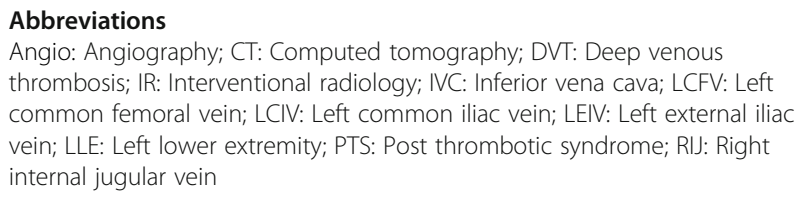
thrombosis; IR: Interventional radiology; IVC: Inferior vena cava; LCFV: Left common femoral vein; LCIV: Left common iliac vein; LEIV: Left external iliac vein; LLE: Left lower extremity; PTS: Post thrombotic syndrome; RIJ: Right internal jugular vein

\section{Acknowledgements}

None.

\section{Authors' contributions}

MMM was responsible for reviewing the patient data, writing the first draft of the manuscript, and creating the figures; KN contributed to review of the case data, selection of images, and revising the manuscript; JAL was responsible for performing the case and revising the manuscript; $C D$ was responsible for clinical management, conception/design of the manuscript, and revising the manuscript; and OA was responsible for performing the case, conception/design of the manuscript, selection of images, and revising the manuscript. All authors agreed to be personally accountable for their own contributions and ensure that questions related to the accuracy or integrity of any part of the work, even ones in which the author was not personally involved, are appropriately investigated, resolved, and the resolution documented in the literature.

\section{Funding}

This study was not supported by any funding.

\section{Availability of data and materials}

Data sharing is not applicable to this article as no datasets were generated or analysed during the current study.

\section{Ethics approval and consent to participate}

For this type of study, informed consent is not required and was IRB exempt.

\section{Consent for publication}

Written informed consent was obtained from the patient for publication of this case report and any accompanying images.

\section{Competing interests}

OA reports receiving speaker fees from Canon Medical, Cook Medical, Cardiva Medical, and Argon Medical, and is also an advisory board member for Boston Scientific. MMM, KN, JAL, and CD declare that they have no competing interests.

\section{Author details}

'Department of Radiology, University of Pennsylvania, 3400 Spruce Street, Philadelphia, PA 19103, USA. '2Department of Radiology, Section of Vascular and Interventional Radiology, University of Chicago Medicine, 5841 S. Maryland Ave, Chicago, IL 60637, USA. ${ }^{3}$ Department of Surgery, Section of Vascular Surgery, University of Chicago Medicine, 5841 S. Maryland Ave, Chicago, IL 60637, USA.
Received: 3 July 2020 Accepted: 2 August 2020

Published online: 11 October 2020

\section{References}

Hage AN, Srinivasa RN, Abramowitz SD, Cooper KJ, Khaja MS, Barnes GD, Chick JFB (2018) Endovascular iliocaval reconstruction for the treatment of iliocaval thrombosis: from imaging to intervention. Vasc Med 23(3):267-275

Haskal ZJ, Duszak R Jr, Furth EE (1996) Transjugular intrahepatic transcaval portosystemic shunt: the gun-sight approach. J Vasc Interv Radiol 7(1):139-142

Ito N, Isfort P, Penzkofer T, Grommes J, Greiner A, Mahnken A (2012) Sharp recanalization for chronic left iliac vein occlusion. Cardiovasc Intervent Radiol 35(4):938-941

McDevitt JL, Srinivasa RN, Gemmete JJ, Hage AN, Srinivasa RN, Bundy JJ, Chick JFB (2019) Approach, technical success, complications, and stent patency of sharp recanalization for the treatment of chronic venous occlusive disease: experience in 123 patients. Cardiovasc Intervent Radiol 42(2):205-212

Soosainathan A, Moore HM, Gohel MS, Davies AH (2013) Scoring systems for the post-thrombotic syndrome. J Vasc Surg 57(1):254-261

Tanaka T, Arai Y, Inaba Y, Inoue M, Nishiofuku H, Anai H, Hori S, Sakaguchi H, Kichikawa K (2014) Current role of hybrid CT/angiography system compared with C-arm cone beam CT for interventional oncology. Br J Radiol 87(1041): 20140126-20140126

Toyoda H, Kumada T, Sone Y (2009) Impact of a unified CT angiography system on outcome of patients with hepatocellular carcinoma. Am J Roentgenol 192(3):766-774

Wadhwa V, Srinivasa RN, Cooper KJ, Hage AN, Bundy JJ, Spencer B, Vadlamudi V, Chick JFB (2018) Endovascular therapy for lower extremity chronic deep venous occlusive disease: state of practice. Semin Interv Radiol 35(4):333-341

Williams ZF, Dillavou ED (2020) A systematic review of venous stents for iliac and venacaval occlusive disease. J Vasc Surg Venous Lymphat Disord 8(1):145-153

\section{Publisher's Note}

Springer Nature remains neutral with regard to jurisdictional claims in published maps and institutional affiliations.

\section{Submit your manuscript to a SpringerOpen ${ }^{\circ}$ journal and benefit from:}

- Convenient online submission

- Rigorous peer review

- Open access: articles freely available online

High visibility within the field

- Retaining the copyright to your article

Submit your next manuscript at $\boldsymbol{\nabla}$ springeropen.com 